\title{
A case of resistant tachycardia in a child with febrile status epilepticus
}

\author{
Satoshi Nakajima ${ }^{1,2}$, Osamu Nomura ${ }^{2}$, Hirokazu Takei ${ }^{2}$, \\ Yusuke Hagiwara' ${ }^{2}$, Naofumi Sumitomo ${ }^{3}$ \\ 'Department of Emergency Medicine, Kyoto Prefectural University of Medicine, Kyoto, Japan \\ ${ }^{2}$ Division of Pediatric Emergency Medicine, Department of Pediatric Emergency and Critical Care Medicine, \\ Tokyo Metropolitan Children's Medical Center, Tokyo, Japan \\ ${ }^{3}$ Division of Cardiology, Tokyo Metropolitan Children's Medical Center, Tokyo, Japan
}

A 5-year-old girl with no medical history presented at the emergency department with febrile status epilepticus (FSE). On arrival, she presented with a generalized tonic seizure and significant tachycardia $(228 \mathrm{bpm})$. The generalized tonic seizure resolved following the administration of intranasal $(0.3 \mathrm{mg} / \mathrm{kg}) /$ intravenous $(0.2 \mathrm{mg} / \mathrm{kg})$ midazolam and fosphenytoin $(22.5 \mathrm{mg} / \mathrm{kg})$, although the tachycardia persisted. A 12-lead electrocardiogram revealed narrow QRS regular tachycardia (Fig. 1), and a pediatric cardiologist was consulted. Intravenous adenosine (0.2 mg/kg) was administered and a definitive diagnosis of atrial tachycardia (AT) was made (Fig. 2). The patient was admitted to the pediatric intensive care unit.

AT is a relatively common arrhythmia in children. ${ }^{1}$ The electrocardiogram shows an abnormal morphology of $\mathrm{P}$ waves, narrow $\mathrm{QRS}$, and a fluctuating RR interval. The abnormal $\mathrm{P}$ wave of patients with AT may not be obvious, and the administration of adenosine is effective for diagnosis: the electrocardiogram demonstrates atrioventricular block, with a constant $\mathrm{P}$ wave as a result of the inhibition of atrioventricular conduction by adenosine and an increase in atrial automaticity.

Tachycardia is seen in almost all cases of FSE caused by an underlying fever, infection, dehydration, or the seizure itself. Furthermore, sympathetic nervous function may be stimulated and/ or trigger cardiac automaticity in patients with status epilepticus. ${ }^{2-5}$ In this case, a diagnosis of AT was made on the basis of persistent tachycardia despite the cessation of the seizures. AT should be considered in patients with FSE if the tachycardia is resistant to anticonvulsive treatment.
Received: October 242017

Revised: November 62017

Accepted: November 62017

Correspondence to: Hirokazu Takei Division of Pediatric Emergency Medicine, Department of Pediatric Emergency and Critical Care Medicine, Tokyo Metropolitan Children's Medical Center, 2-8-29, Musashidai, Fuchu, Tokyo 183-8561, Japan E-mail: paquottehiro@yahoo.co.jp ORCID

http://orcid.org/0000-0001-7651-6677

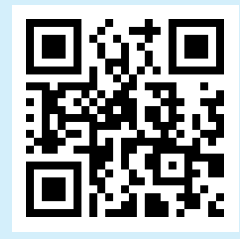

How to cite this article:

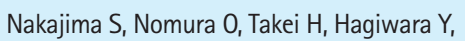
Sumitomo N. A case of resistant tachycardia in a child with febrile status epilepticus. Clin Exp Emerg Med 2018;5(4):286-287.

This is an Open Access article distributed under the terms of the Creative Commons Attribution Non-Commercial License (http:// creativecommons.org/licenses/by-nc/4.0/). 


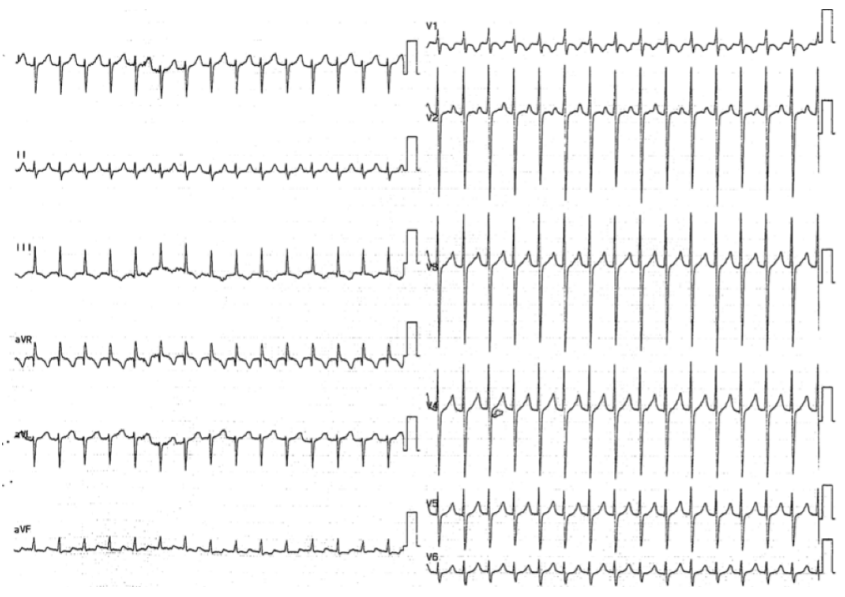

Fig. 1. Twelve-lead electrocardiogram showing regular, narrow QRS tachycardia, with a heart rate of $197 / \mathrm{min}$.

\section{CONFLICT OF INTEREST}

No potential conflict of interest relevant to this article was reported.

\section{ACKNOWLEDGMENTS}

We would like to thank Mr. James Robert Valera for his help with editing the manuscript.

\section{REFERENCES}

1. Blomstrom-Lundqvist C, Scheinman MM, Aliot EM, et al. ACC/ AHA/ESC guidelines for the management of patients with supraventricular arrhythmias. J Am Coll Cardiol 2003;42:1493531.
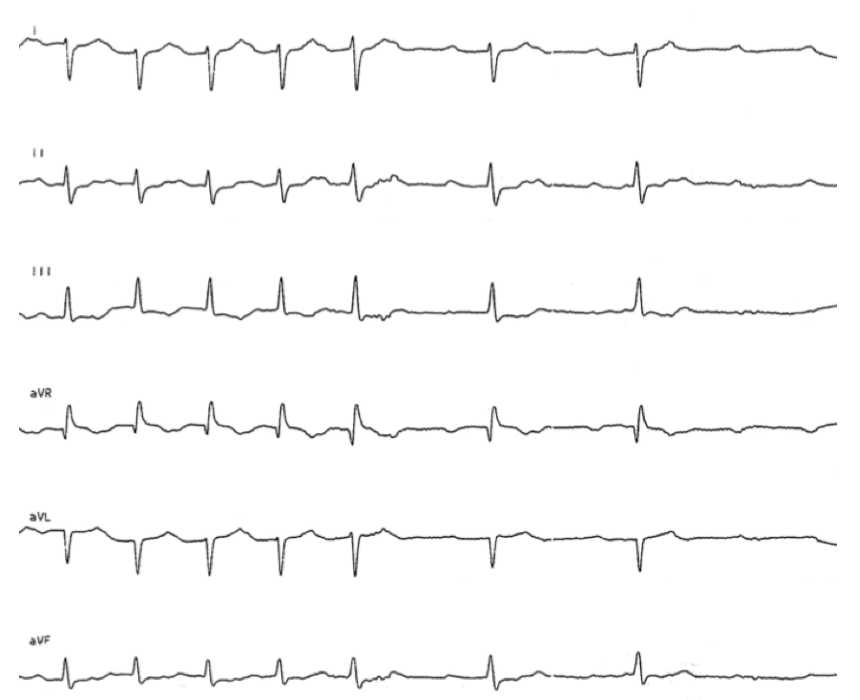

Fig. 2. Twelve-lead electrocardiogram obtained during the administration of an intravenous bolus of adenosine, showing uniform $P$ waves and AV block.

2. van der Lende M, Surges R, Sander JW, Thijs RD. Cardiac arrhythmias during or after epileptic seizures. J Neurol Neurosurg Psychiatry 2016;87:69-74.

3. Tao JX, Yung I, Lee A, Rose S, Jacobsen J, Ebersole JS. Tonic phase of a generalized convulsive seizure is an independent predictor of postictal generalized EEG suppression. Epilepsia 2013;54:858-65.

4. Pinto KG, Scorza FA, Arida RM, et al. Sudden unexpected death in an adolescent with epilepsy: all roads lead to the heart? Cardiol J 2011;18:194-6.

5. Rice EH, Sombrotto LB, Markowitz JC, Leon AC. Cardiovascular morbidity in high-risk patients during ECT. Am J Psychiatry 1994;151:1637-41. 